\title{
Inflammatory rheumatic diseases and pregnancy
}

\author{
Katarzyna Klimaszyk®, Ewa Wender-Ozegowska®, Malgorzata Kedzia® \\ Department of Reproduction, Poznan University of Medical Sciences, Poland
}

\begin{abstract}
Pregnancy in a patient diagnosed with systemic connective tissue disorder is a challenge that requires a close co-operation between a rheumatologist and gynaecologist. Good control over the activity of the underlying condition and the choice of appropriate time for planning a pregnancy have direct effect on the pregnancy results in these patients. Applying gynaecological supervision adequate to the increased risk of complications is also very important.

The aim of this study is to present the current knowledge on the care over pregnant patients with systemic connective tissue diseases and to draw attention to the importance of pregnancy planning in this group of patients.
\end{abstract}

Key words: inflammatory rheumatic diseases; pregnancy; lupus erythematosus; adverse pregnancy outcomes

Ginekologia Polska 2021; 92, 9: 663-667

\section{INTRODUCTION}

Systemic autoimmune connective tissue diseases are a heterogeneous group of rheumatological conditions with common pathogenesis: autoimmune inflammation of the connective tissue. Depending on a disease, symptoms from many systems and organs determine various clinical manifestations.

According to the 1983 American Rheumatism Association (ARA) classification of rheumatological diseases, systemic connective tissue diseases include:

Systemic lupus erythematosus, rheumatoid arthritis, juvenile idiopathic arthritis, scleroderma, polymyositis, and dermatomyositis, vasculitis, Sjögren's syndrome, overlap syndromes, including unspecified and mixed connective tissue disease, and others.

Typical age of diagnosis of systemic connective tissue diseases are typically found in patients between 20 and 40 years old, i.e., in their reproductive age. Rheumatic diseases, with rheumatoid arthritis being the most common one, are rare. Their prevalence is estimated at 0.001 to $1.0 \%$ [1].

The reason why connective tissue diseases affect women more often than men is unknown. Due to the rare occurrence of these disorders, resulting in limited experience in care over pregnant women with connective tissue diseases and the possible deterioration of mother and foetus condition it seems that these patients should be treated at reference centres.
Based on the analysis of the course of pregnancy, and pregnancy outcomes of patients suffering from connective tissue disorders, pregnancy in this group of women is associated with a higher risk of complications and adverse pregnancy outcomes compared to the healthy population. The principal factors affecting the risk include organ complications and high activity of the underlying disease [2,3].

Effective symptom control due to proper pharmacotherapy, motivates patients to make a conscious decision to get pregnant.

The aim of this study is to present the current knowledge on the care over pregnant patients with systemic connective tissue diseases and to draw attention to the importance of pregnancy planning in this group of patients.

\section{PREGNANCY MANAGEMENT \\ Preparation for getting pregnant \\ The time of becoming pregnant}

Proper timing for trying to get pregnant in the case of patients with systemic connective tissue diseases is crucial. It should be the time of low disease activity, obtained with pharmacotherapy that may be continued safely during pregnancy [4]. The recommended period of symptom reduction, meeting the remission criteria, prior to getting pregnant differs between various diseases. In the case of lupus erythematosus, it is at least six months [5]. In patients diagnosed with other connective tissue diseases, without

\footnotetext{
Corresponding author:

Katarzyna Klimaszyk

Department of Reproduction, Poznan University of Medical Sciences, 333 Polna St, 60-535 Poznan, Poland

e-mail: kedjaworska@gmail.com
}

This article is available in open access under Creative Common Attribution-Non-Commercial-No Derivatives 4.0 International (CC BY-NC-ND 4.0) license, allowing to download articles and share them with others as long as they credit the authors and the publisher, but without permission to change them in any way or use them commercially. 
extraarticular symptoms, three months of remission are deemed sufficient.

\section{Pharmacotherapy}

Another important element of preparation involves the analysis of medications used by the patient and the possibility of treatment continuation during pregnancy. The necessity to discontinue teratogenic drugs, if they are used to maintain remission, is associated with the risk of increased disease activity. Therefore, it is important that patients can continue their treatment and control the activity of the underlying disease also during pregnancy. Literature data demonstrate that in patients with systemic lupus erythematosus using hydroxychloroquine discontinuation of the therapy is a significant risk factor for exacerbation of the underlying disease and adverse pregnancy outcomes [6-8]. Therefore, all pregnant patients with lupus should receive hydroxychloroquine, unless it is contraindicated.

The disease controlling drugs with known teratogenic effect that should be discontinued in advance before getting pregnant include methotrexate - three months; cyclophosphamide - three months; mycophenolate mofetil six weeks [9-11].

It is recommendable to discontinue the drugs that are contraindicated in pregnancy, whose effects on pregnancy have not been sufficiently studied, at least one month prior to the planned pregnancy. They include targeted synthetic disease-modifying antirheumatic drugs [9].

In the case of biologic drugs, their ability to penetrate the foetal circulation is varied; therefore, only some of them are approved for use in pregnancy [12].

Continuation of certain TNF inhibitors during pregnancy is acceptable, and the recommended time for their discontinuation before the planned delivery depends on the half-life of a given drug. This is to ensure that during the delivery the medication will not be present in the child's organism, as it may be a risk factor for infections in the case of using live vaccines [13].

\section{Organ dysfunction}

Another step involves the assessment of organ dysfunction associated with the underlying disease. If the patient had a history of organ failure at any time, despite the subsequent improvement or normalisation of the organ's function, this fact significantly increases the risk of pregnancy complications, both foetal and maternal [14].

In the case of pulmonary hypertension, interstitial lesions in the lungs, heart failure, renal failure or multidrug-resistant hypertension in a previous pregnancy, the decision regarding pregnancy should be taken by a multidisciplinary group of experts, due to the risk of increased pregnancy complications.

\section{Presence of anti-SSA and anti-SSB antibodies}

Another aspect to be considered when preparing for pregnancy is the assessment of anti-SSA and anti-SSB antibodies. Anti- Sjögren's syndrome-related antigen-A antibodies (anti-SSA) /RO and anti-SSB/LA antibodies may be present not only in patients with Sjögren's disease, but also with other systemic connective tissue diseases [15].

These antibodies actively penetrate the placental barrier from approximately 16 th week of gestation, which may cause atrioventricular blockage in the heart of the foetus, or neonatal lupus [16]. In most cases, heart blockage develops between 18 and 24 weeks of gestation. The risk of complete heart blockage in the foetus of an SSA-positive or SSB-positive mother is two percent; however, it increases to $18 \%$ if a blockage occurred already in a previous pregnancy [17]. Complete foetal heart blockage is the most dangerous complication, almost always requiring cardiac stimulation in the neonate, due to the irreversible changes in the electrical conduction system of the heart.

Determination of the anti-SSA or anti-SSB status of the mother already when planning pregnancy or in its early stage will enable proper supervision - ultrasound assessment of the atrioventricular conductivity in the heart of the foetus.

If an early blockage is detected, therapy with steroids penetrating the placental barrier (dexamethasone, betamethasone) should be applied. [18]. However, the effectiveness of this treatment was not clearly demonstrated.

The use of hydroxychloroquine was associated with a proven reduction of the rate of atrioventricular block in the foetuses of anti-SSA-positive and anti-SSB-positive mothers, as well as with decreased recurrence of this complication in subsequent pregnancies [19-21].

Skin, haematological and hepatic manifestations of neonatal lupus in most cases resolve after six to nine months following the birth, when maternal antibodies cease to circulate in the child's organism [22].

\section{Obstetric history}

A detailed analysis of the previous obstetric history of the patient with systemic connective tissue disease is an essential element of preparation for pregnancy. If the information from the obstetric history reveals a negative pregnancy outcome, the cause should be established, and it should be determined whether it coincided with exacerbation of the underlying disease. The patient should be informed that proper preparation for pregnancy and appropriate period of symptom remission increase the chances of successful pregnancy outcome.

Negative pregnancy outcomes that meet one of the clinical criteria of antiphospholipid syndrome (APS) require verification of this diagnosis in laboratory tests before the 
patient gets pregnant again. Patient's blood serum should be tested for antiphospholipid antibodies (anticardiolipin antibody, beta-glycoprotein 1 antibody and lupus anticoagulant). The diagnosis of antiphospholipid syndrome must be supported by two positive results for at least one of three antibodies at medium or high titres, performed at least 12 weeks apart, together with a clinical criterion [23].

Presence of anticardiolipin antibody doubles the risk of venous thrombosis in patients with systemic lupus. The risk is six times higher in patients with positive test results for lupus anticoagulant, compared to lupus patients without these antibodies [24]. In patients with antiphospholipid syndrome, anticoagulatory prevention with low-molecular-weight heparin is recommended throughout the pregnancy and the postpartum period is recommended.

In the context of anti-SSA/anti-SSB antibodies, it is always necessary to ask patients about the occurrence of atrioventricular blockage or neonatal lupus in their children.

\section{The effect of the underlying disease on the course of pregnancy}

Due to a limited prevalence of connective tissue diseases, their effect on the course of pregnancy has been studied most extensively in the population of patient with the most common disorders within this group: lupus and rheumatoid arthritis. Other connective tissue diseases also increase the risk of pregnancy complications, especially when the activity of the disease is high, antibodies are present, or organ complications occur.

The data from retrospective studies indicate that in patients with RA pregnancy complications, i.e., pregnancy-induced hypertension, pre-eclampsia, FGR and premature birth occur significantly more often than in the healthy population of pregnant women. These pregnancies also required Caesarean section delivery more frequently [25-27].

A meta-analysis of studies from the years 2001-2016, including 3,395 patients with lupus demonstrated nearly a double increase of the relative risk (RR) of pregnancy-induced hypertension and pre-eclampsia, over three times higher risk or premature birth, and over four times higher risk of growth retardation in the child [28].

\section{Pregnancy supervision}

Care over a patient with a systemic connective tissue disease should be provided by a multidisciplinary team, including a rheumatologist, obstetrician and, depending on the organ complications specific for the patient, specialists in other fields of medicine.

For a patient with a connective tissue disease pregnancy is a special time, and it requires a regular monitoring of disease activity. Systematic control of the disease activity markers conducted by the patient's rheumatologist will enable early detection of exacerbations, and potential modification of pharmacotherapy. According to the presence of risk factors, determined before the conception, the supervision over the patient must be individualised. In addition to the gynaecological examination and blood pressure tests performed at every visit, laboratory studies should be performed to assess renal function (creatinine, general urinalysis, presence of protein in urine), liver function (AIAT, AspAT), and complete blood count. If arterial hypertension occurs, it should be controlled regularly, both by Holter and home blood pressure monitoring to optimise pharmacology treatment.

All pregnant patient with a systemic connective tissue disease, especially lupus erythematosus, are at high risk of pre-eclampsia, so preventive treatment with low doses of acetylsalicylic acid ( $\leq 150 \mathrm{mg}$ ) is recommended [5, 29]. The suggested time for initiation of the prophylactic therapy is $12-16$ weeks of pregnancy.

The factors additionally increasing the risk of pre-eclampsia in patients with lupus include active disease at six months prior to conception, lupus nephritis, chronic hypertension, presence of antiphospholipid antibodies, low levels of complement components and thrombocytopaenia [30]. Doppler ultrasound examination of the flow in the uterine arteries in the second trimester is also recommended. Presence of bilateral early diastolic notches in these arteries between 23 and 25 weeks of gestation is a predictive factor for pre-eclampsia and pregnancy hypertension [31].

Differentiation between pre-eclampsia and lupus nephritis poses a significant challenge in the management of patients with lupus. In both cases, the clinical manifestation may include proteinuria, oedema, impaired renal function, hypertension and thrombocytopaenia. Lupus nephritis is characterised by reduced concentrations of complement components $\mathrm{C} 3$ and $\mathrm{C} 4$, increased titres of anti-dsDNA antibodies, active urinary sediment (presence of dysmorphic erythrocytes, erythrocyte casts and granular casts), and manifestation of other dermatological, articular and haematological symptoms of disease exacerbation. In pre-eclampsia, the levels of complement components $\mathrm{C} 3$ and C4 typically increases [32]. If the two conditions cannot be differentiated clinically, a kidney biopsy may be required. The only effective management in the case of intensified symptoms posing a threat to the lives of the mother or the child due to severe pre-eclampsia is premature delivery of the child, which may also be necessary to administer proper immunosuppressants for exacerbated nephritis.

In patients diagnosed with antiphospholipid syndrome, anticoagulatory prevention during pregnancy with low-molecular-weight heparin is recommended [33]. These pregnant patients, and women with other rheumatic diseases, 
especially with systemic lupus, should receive antiplatelet therapy with low doses of aspirin.

In patients positive for anti-SSA and anti-SSB antibodies ultrasound monitoring of the atrioventricular conduction time in the foetus is required. The conduction time can be measured in an ultrasound examination using the M-mode technique, pulsed Doppler and tissue Doppler. Normal atrioventricular conduction time in a foetus is $110-150 \mathrm{~ms}$ [34]. Following the recommendations of the American Heart Association, monitoring of the foetus of a patient positive for anti-SSA or anti-SSB antibodies should start at 16 weeks of gestation. Measurements should be performed weekly, until 24 weeks of gestation.

\section{SUMMARY}

Despite pregnant women diagnosed with inflammatory rheumatic diseases are in the group of greater risk of adverse pregnancy outcomes, following up to date principles of pregnancy planning and supervision can rise the chance of motherhood of those patients.

Due to the risk of disease exacerbation and sudden deterioration of both mother and feats condition those patients require multidisciplinary monitoring and should be referred to reference centre in case of the necessity of advance obstetric and neonatal care.

\section{REFERENCES}

1. Sangha O. Epidemiology of rheumatic diseases. Rheumatology (Oxford). 2000; 39 Suppl 2: 3-12, doi: 10.1093/rheumatology/39.suppl_2.3, indexed in Pubmed: 11276800.

2. Østensen M, Andreoli L, Brucato A, et al. State of the art: Reproduction and pregnancy in rheumatic diseases. Autoimmun Rev. 2015; 14(5):376386, doi: 10.1016/j.autrev.2014.12.011, indexed in Pubmed: 25555818.

3. Bharti B, Lee SJ, Lindsay SP, et al. Disease Severity and Pregnancy Outcomes in Women with Rheumatoid Arthritis: Results from the Organization of Teratology Information Specialists Autoimmune Diseases in Pregnancy Project. J Rheumatol. 2015; 42(8): 1376-1382, doi: 10.3899/jrheum. 140583, indexed in Pubmed: 25877497.

4. de Man YA, Hazes JMW, van der Heide $\mathrm{H}$, et al. Association of higher rheumatoid arthritis disease activity during pregnancy with lower birth weight: results of a national prospective study. Arthritis Rheum. 2009; 60(11): 3196-3206, doi: 10.1002/art.24914, indexed in Pubmed: 19877045.

5. Andreoli L, Bertsias GK, Agmon-Levin N, et al. EULAR recommendations for women's health and the management of family planning, assisted reproduction, pregnancy and menopause in patients with systemic lupus erythematosus and/or antiphospholipid syndrome. Annals of the Rheumatic Diseases. 2016; 76(3): 476-485, doi: 10.1136/annrheumdis-2016-209770.

6. Cortés-Hernández J, Ordi-Ros J, Paredes F, et al. Clinical predictors of fetal and maternal outcome in systemic lupus erythematosus: a prospective study of 103 pregnancies. Rheumatology (Oxford). 2002; 41 (6): 643-650, doi: 10.1093/rheumatology/41.6.643, indexed in Pubmed: 12048290.

7. Clowse MEB, Magder L, Witter F, et al. Hydroxychloroquine in lupus pregnancy. Arthritis Rheum. 2006; 54(11):3640-3647, doi: 10.1002/art.22159, indexed in Pubmed: 17075810.

8. Eudy AM, Siega-Riz AM, Engel SM, et al. Effect of pregnancy on disease flares in patients with systemic lupus erythematosus. Ann Rheum Dis. 2018; 77(6): 855-860, doi: 10.1136/annrheumdis-2017-212535, indexed in Pubmed: 29463519.

9. Götestam Skorpen C, Hoeltzenbein M, Tincani A, et al. The EULAR points to consider for use of antirheumatic drugs before pregnancy, and during pregnancy and lactation. Ann Rheum Dis. 2016; 75(5): 795-810, doi: 10.1136/annrheumdis-2015-208840, indexed in Pubmed: 26888948.

10. Coscia LA, Armenti DP, King RW, et al. Update on the Teratogenicity of Maternal Mycophenolate Mofetil. J Pediatr Genet. 2015; 4(2): 42-55, doi: 10.1055/s-0035-1556743, indexed in Pubmed: 27617117.

11. Leroy $C$, Rigot JM, Leroy $M$, et al. Immunosuppressive drugs and fertility. Orphanet J Rare Dis. 2015; 10: 136, doi: 10.1186/s13023-015-0332-8, indexed in Pubmed: 26490561.

12. Youngstein $T$, Hoffmann $P$, Gül A, et al. International multi-centre study of pregnancy outcomes with interleukin-1 inhibitors. Rheumatology (Oxford). 2017; 56(12): 2102-2108, doi: 10.1093/rheumatology/kex305, indexed in Pubmed: 28968868.

13. Giles I, Yee CS, Gordon C. Stratifying management of rheumatic disease for pregnancy and breastfeeding. Nat Rev Rheumatol. 2019; 15(7): $391-$ 402, doi: 10.1038/s41584-019-0240-8, indexed in Pubmed: 31186540.

14. Kallur SD, Patil Ba, Reddy P, et al. P. K. Organ dysfunction and organ failure as predictors of outcomes of severe maternal morbidity in an obstetric intensive care unit. J Clin Diagn Res. 2014; 8: OC06-OC08.

15. Franceschini F, Cavazzana I. Anti-Ro/SSA and La/SSB antibodies. Autoimmunity. 2005; 38(1): 55-63, doi: 10.1080/08916930400022954, indexed in Pubmed: 15804706

16. Simister NE, Story $\mathrm{CM}$, Chen $\mathrm{HL}$, et al. An IgG-transporting Fc receptor expressed in the syncytiotrophoblast of human placenta. Eur J Immunol. 1996; 26(7): 1527-1531, doi: 10.1002/eji.1830260718, indexed in Pubmed: 8766556.

17. Costedoat-Chalumeau N, Amoura Z, Lupoglazoff JM, et al. Outcome of pregnancies in patients with anti-SSA/Ro antibodies: a study of 165 pregnancies, with special focus on electrocardiographic variations in the children and comparison with a control group. Arthritis Rheum. 2004; 50(10): 3187-3194, doi: 10.1002/art.20554, indexed in Pubmed: 15476223.

18. Clowse MEB, Eudy AM, Kiernan E, et al. The prevention, screening and treatment of congenital heart block from neonatal lupus: a survey of provider practices. Rheumatology (Oxford). 2018; 57(suppl_5):v9-vv17, doi: 10.1093/rheumatology/key141, indexed in Pubmed: 30137589.

19. Izmirly PM, Costedoat-Chalumeau N, Pisoni CN, et al. Maternal use of hydroxychloroquine is associated with a reduced risk of recurrent anti-SSA/Ro-antibody-associated cardiac manifestations of neonatal lupus. Circulation. 2012; 126(1): 76-82, doi: 10.1161/CIRCULATIONAHA.111.089268, indexed in Pubmed: 22626746.

20. Izmirly PM, Kim MY, Llanos $C$, et al. Evaluation of the risk of anti-SSA/Ro-SSB/La antibody-associated cardiac manifestations of neonatal lupus in fetuses of mothers with systemic lupus erythematosus exposed to hydroxychloroquine. Ann Rheum Dis. 2010;69(10): 1827-1830, doi: 10.1136/ard.2009.119263, indexed in Pubmed: 20447951.

21. Martínez-Sánchez N, Pérez-Pinto S, Robles-Marhuenda Á, et al. Obstetric and perinatal outcome in anti-Ro/SSA-positive pregnant women: a prospective cohort study. Immunol Res. 2017; 65(2): 487-494, doi: 10.1007/s12026-016-8888-5, indexed in Pubmed: 28138914.

22. Zuppa AA, Riccardi R, Frezza S, et al. Neonatal lupus: Follow-up in infants with anti-SSA/Ro antibodies and review of the literature. Autoimmun Rev. 2017; 16(4): 427-432, doi: 10.1016/j.autrev.2017.02.010, indexed in Pubmed: 28212920.

23. Miyakis S, Lockshin MD, Atsumi T, et al. International consensus statement on an update of the classification criteria for definite antiphospholipid syndrome (APS). J Thromb Haemost. 2006; 4(2): 295-306, doi: 10.1111/j.1538-7836.2006.01753.x, indexed in Pubmed: 16420554.

24. Wahl DG, Guillemin F, de Maistre $E$, et al. Risk for venous thrombosis related to antiphospholipid antibodies in systemic lupus erythematosus--a meta-analysis. Lupus. 1997; 6(5): 467-473, doi: 10.1177/096120339700600510, indexed in Pubmed: 9229367.

25. Lin HC, Chen SF, Lin HC, et al. Increased risk of adverse pregnancy outcomes in women with rheumatoid arthritis: a nationwide population-based study. Ann Rheum Dis. 2010; 69(4): 715-717, doi: 10.1136/ard.2008.105262, indexed in Pubmed: 19406733.

26. Skomsvoll JF, Ostensen M, Irgens LM, et al. Obstetrical and neonatal outcome in pregnant patients with rheumatic disease. Scand J Rheumatol Suppl. 1998; 107: 109-112, doi: 10.1080/03009742.1998.11720781, indexed in Pubmed: 9759146.

27. Wolfberg AJ, Lee-Parritz A, Peller AJ, et al. Association of rheumatologic disease with preeclampsia. Obstet Gynecol. 2004; 103(6): 1190-1193, doi: 10.1097/01.AOG.0000126279.87151.e1, indexed in Pubmed: 15172851.

28. Bundhun PK, Soogund MZ, Huang F. Impact of systemic lupus erythematosus on maternal and fetal outcomes following pregnancy: 
A meta-analysis of studies published between years 2001-2016. J Autoimmun. 2017; 79: 17-27, doi: 10.1016/j.jaut.2017.02.009, indexed in Pubmed: 28256367.

29. Henderson JT, Whitlock EP, O'Connor E, et al. Low-dose aspirin for prevention of morbidity and mortality from preeclampsia: a systematic evidence review for the U.S. Preventive Services Task Force. Ann Intern Med. 2014; 160(10): 695-703, doi: 10.7326/M13-2844, indexed in Pubmed: 24711050.

30. Bramham K, Hunt BJ, Bewley S, et al. Pregnancy outcomes in systemic lupus erythematosus with and without previous nephritis. J Rheumatol. 2011; 38(9): 1906-1913, doi: 10.3899/jrheum.100997, indexed in Pubmed: 21632681.

31. Espinoza J, Kusanovic JP, Bahado-Singh R, et al. Should bilateral uterine artery notching be used in the risk assessment for preeclampsia, small-for-gestational-age, and gestational hypertension? J Ultrasound Med. 2010; 29(7): 1103-1115, doi: 10.7863/jum.2010.29.7.1103, indexed in Pubmed: 20587434.

32. Soh MC, Nelson-Piercy C, Soh MC, et al. High-risk pregnancy and the rheumatologist. Rheumatology (Oxford). 2015; 54(4): 572-587, doi: 10.1093/rheumatology/keu394, indexed in Pubmed: 25477056.

33. Fouda UM, Sayed AM, Abdou AMA, et al. Enoxaparin versus unfractionated heparin in the management of recurrent abortion secondary to antiphospholipid syndrome. Int J Gynaecol Obstet. 2011; 112(3): 211-215, doi: 10.1016/j.ijgo.2010.09.010, indexed in Pubmed: 21251653.

34. Hamela-Olkowska A, Dangel J. Ocena czasu przewodzenia przedsionkowo-komorowego metodą Dopplera pulsacyjnego u zdrowych płodów. Ginekol Pol. 2009; 80: 584-589. 